Discussion Paper No. 893

\title{
EXCHANGE-RATE ADJUSTMENT \\ AND \\ MACROECONOMIC INTERDEPENDENCE \\ BETWEEN STAGNANT AND \\ FULLY EMPLOYED COUNTRIES
}

\author{
Yoshiyasu Ono
}

\author{
January 2014 \\ Revised November 2014
}

The Institute of Social and Economic Research

Osaka University

6-1 Mihogaoka, Ibaraki, Osaka 567-0047, Japan 


\title{
Exchange-rate adjustment and macroeconomic interdependence between stagnant and fully employed countries*
}

\author{
by \\ Yoshiyasu $\mathrm{Ono}^{\dagger}$
}

\begin{abstract}
This paper presents a two-country two-commodity dynamic macroeconomic model with free international asset trade in which one country achieves full employment and the other suffers long-run unemployment. Own and spill-over effects of changes in policy, technological and preference parameters emerge through exchange-rate adjustment. The parameter changes that worsen the stagnant country's current account depreciate the home currency, expand home employment and improve the foreign terms of trade, making both countries better off. The stagnant country's foreign aid to the fully employed country also yields the same beneficial effects on both countries.
\end{abstract}

JEL classification: F32, F41, F35

Keywords: long-run unemployment, current account, liquidity trap, exchange rate, fiscal expansion, foreign aid.

\footnotetext{
* This research is financially supported by the Grants-in-Aid for Scientific Research, the Japan Society for Promotion of Science (JSPS). A significant part of this research was done while the author visited the Center for Economic Studies (CES) of the University of Munich (LMU). The author thanks G. Illing and the participants of the macroeocnomics seminar held in the Univeristy of Munich for their valuable comments. Helpful comments by the participants of the INFINITI Conference on International Finance 2014 are also gratefully appreciated.

${ }^{\dagger}$ Institute of Social and Economic Research, Osaka University, 6-1, Mihogaoka, Ibaraki, Osaka 567-0047, JAPAN. E-mail: ono@iser.osaka-u.ac.jp.
} 


\section{Introduction}

In a closed economy, an increase in productivity obviously expands national income and increases welfare if full employment prevails. In a two-country setting it benefits not only the home country but also the foreign country because it lowers the relative price of the home commodity and improves the foreign country's terms of trade. An increase in home government purchases works as if the home country's productivity decreased, and harms both countries.

If the two countries suffer long-run economic stagnation due to aggregate demand deficiency, however, the result is quite different. Ono $(2006,2014)$ presents a two-country dynamic model with persistent unemployment that arises under a liquidity trap and shows that an increase in the home country's productivity excessively improves the current account and leads the home currency to appreciate so much that home employment and consumption decrease, which makes the home country worse off. The home currency appreciation in turn causes the foreign country's employment and national income to increase and benefits the foreign country. An increase in home government purchases worsens the home current account and leads the home currency to depreciate, which improves home employment and reduces foreign employment. Consequently, the home country is better off while the foreign country is worse off.

There is yet another important case: one country faces persistent deficiency of aggregate demand while the other country realizes full employment. It may in particular be relevant between a developed country that faces persistent stagnation due to a liquidity trap, e.g. Japan for two decades, and an emerging country that has large demand and enjoys high growth, e.g. China. This paper focuses on this case and examines the effects on the two countries of changes in various parameters including productivity and government purchases. The effects of foreign aid on the two countries are also examined. 
It is naturally believed that foreign aid makes the donor country worse off and the recipient country better off. Due to this belief the foreign aid budget is usually cut when a donor country faces persistent stagnation, as Japan did in the 'Lost Decades'. However, this belief is true only if full employment prevails in both countries. If both countries face stagnation, the donor country is better off while the recipient country is worse off as a result of exchange-rate adjustment (see Ono, 2014). ${ }^{1}$

The benefits of foreign aid for both recipient and donor countries in the asymmetric case were discussed in some important policy decisions. The Marshall Plan in 1947 was an example. George C. Marshall, the US Secretary of State at that time, proposed an aid of \$20 billion to European countries that had significantly lost supply capacities in World War II and faced a serious shortage of supply. He then stated that it would benefit not only European consumers by enabling them to import US commodities but also US producers and workers by creating a market. ${ }^{2}$ In the context of the North-South problem, the Independent Commission on International Development Issues, a panel lead by former German Chancellor Willy Brandt in the early 1980s (the Brandt commission, 1980, 1983), argued that foreign aid from the North to the South would benefit the donors as well as the recipients through not only stabilizing political/security situations but also creating import demand and expanding employment in the North. ${ }^{3}$ This paper examines the validity of those statements in a dynamic macroeconomic framework and finds that foreign aid makes both the recipient and donor countries better off if

\footnotetext{
${ }^{1}$ In the literature such a controversial case has been mentioned as a transfer paradox. The paradox arises through not an expansion of employment but a change in the terms of trade with full employment. It arises only in the case of Walrasian instability, multiple equilibia or some distortions in a two-country case. See Bhagwati et al $(1983,1985)$ for a general analysis of the transfer paradox with distortions in static two-country and three-country frameworks. Polemarchakis (1983) extended it to an $n$-country economy. The paradoxical case in this paper arises through a change in employment.

${ }^{2}$ He stated: "The Marshall Plan, it should be noted, benefited the American economy as well. The money would be used to buy goods from the United States, and they had to be shipped across the Atlantic on American merchant vessels.” See Congressional Record, 30 June 1947.

${ }^{3}$ This issue was treated by Ono (2007) but he used CES utility functions. This paper extends that analysis to the case of general homothetic utility.
} 
the former achieves full employment and the latter faces persistent deficiency of aggregate demand.

The stagnation considered in the present analysis is not a temporary one but a persistent one due to aggregate demand deficiency with a liquidity trap. In the recent literature most studies regard macroeconomic fluctuations as caused by firms’ and labor unions' monopolistic pricing a la Calvo (1983) and explore small perturbations due to unanticipated policy and technology shocks around the long-run steady state. They are e.g. Yun (1996), Erceg et al. (2000), Smets and Wouters (2003, 2005, 2007), Christiano et al. (2005), and Adolfson et al. (2007, 2008). They never consider any demand deficiency in either the adjustment process or the steady state. The possibility of market disequilibrium is explicitly analyzed by Krugman (1998) in a closed economy setting and Obstfeld and Rogoff (1995) and Hau (2000) in an open economy setting. ${ }^{4}$ In these models, however, demand deficiency occurs only for a period in which an unanticipated exogenous shock occurs and prices are predetermined, and disappears in all the periods that follow.

While these models may well fit to analyze short-run macroeconomic fluctuations, the present paper focuses on such long-run stagnation as Japan's Lost Decades and EU countries' Great Recession triggered by the financial crisis of 2008. In the recent IMF annual conference Summers (2013) warned against relying too much on the DSGE approach in solving economic crises and emphasized the need to work on long-run recessions rather than short-run business fluctuations. This paper follows this line of thought and considers a long-run stagnation due to aggregate demand deficiency.

\footnotetext{
${ }^{4}$ The latter is called new open economy macroeconomic models. See Lane (2001) for an extensive survey on such models.
} 


\section{The model}

There are two countries, the home and foreign countries. The home production sector specializes in commodity 1 and the foreign one in commodity 2. Both of them use only labor to produce respective commodities with constant productivity $\theta_{1}$ and $\theta_{2}^{*}$.

The household sectors of the two countries have the same utility function of the two commodities. The function is homothetic and hence for a given level of consumption expenditure $c$ (or $\left.c^{*}\right)$ it can be summarized as

$$
u(c) \equiv \hat{u}\left(c_{1}, c_{2}\right), u\left(c^{*}\right) \equiv \widehat{u}\left(c_{1}^{*}, c_{2}^{*}\right)
$$

where $c_{i}$ (or $c_{i}^{*}$ ) is the consumption of commodity $i(i=1,2)$ that satisfies

$$
\begin{gathered}
p_{1}(\omega) c_{1}=\delta(\omega) c, \quad p_{2}(\omega) c_{2}=[1-\delta(\omega)] c, \\
p_{1}(\omega) c_{1}^{*}=\delta(\omega) c^{*}, \quad p_{2}(\omega) c_{2}^{*}=[1-\delta(\omega)] c^{*}, \\
1>\delta(\omega)>0, \quad \delta^{\prime}(\omega)>0 .
\end{gathered}
$$

$\omega$ is the relative price and $p_{i}(\omega)$ is the real price of commodity $i(i=1,2)$ :

$$
\begin{gathered}
p_{1}(\omega)=\frac{P_{1}}{P}=\frac{P_{1}^{*}}{P^{*}}, \quad p_{2}(\omega)=\frac{P_{2}}{P}=\frac{P_{2}^{*}}{P^{*}}=\omega p_{1}(\omega), \\
P_{1}^{*}=\frac{P_{1}}{\epsilon}, \quad P_{2}=\epsilon P_{2}^{*},
\end{gathered}
$$

where $P$ and $P^{*}$ are the two countries' general price indices, $P_{i}$ and $P_{i}^{*}$ are the home and foreign nominal prices of commodity $i$ measured in each currency, and $\epsilon$ is the nominal exchange rate, which satisfies

$$
P=\epsilon P^{*} \text {. }
$$

The time derivative of this equation gives

$$
\pi=\frac{\dot{\epsilon}}{\epsilon}+\pi^{*}
$$

where $\pi$ and $\pi^{*}$ are respectively the two countries' inflation rates. Therefore, from the non-arbitrage condition between home and foreign assets: 


$$
R=\frac{\dot{\epsilon}}{\epsilon}+R^{*}
$$

where $R$ and $R^{*}$ respectively represent the home and foreign nominal interest rates, one obtains

$$
R-\pi=r=R^{*}-\pi^{*},
$$

implying that the real interest rate $r$ is internationally the same.

Because the home and foreign general price indices $P$ and $P^{*}$ satisfy

$$
\frac{d P}{P}=\delta(\omega) \frac{d P_{1}}{P_{1}}+(1-\delta(\omega)) \frac{d P_{2}}{P_{2}}, \frac{d P^{*}}{P^{*}}=\delta(\omega) \frac{d P_{1}^{*}}{P_{1}^{*}}+(1-\delta(\omega)) \frac{d P_{2}^{*}}{P_{2}^{*}},
$$

as shown by Deaton and Muellbauer (1980, p.175), from (2) one finds

$$
\begin{gathered}
0=\delta(\omega) \frac{p_{1}^{\prime}(\omega)}{p_{1}(\omega)}+(1-\delta(\omega)) \frac{p_{2}^{\prime}(\omega)}{p_{2}(\omega)}, \\
1+\frac{\omega p_{1}^{\prime}}{p_{1}}=\frac{\omega p_{2}^{\prime}}{p_{2}} .
\end{gathered}
$$

These two equations yield

$$
\delta=1+\frac{\omega p_{1}^{\prime}}{p_{1}}=\frac{\omega p_{2}^{\prime}}{p_{2}} .
$$

The home and foreign representative households have the same subjective discount rate $\rho$ and the same liquidity preference $v(\cdot)$. They maximize each utility functional:

$$
\int_{0}^{\infty}[u(c)+v(m)] \exp (-\rho t) d t, \quad \int_{0}^{\infty}\left[u\left(c^{*}\right)+v\left(m^{*}\right)\right] \exp (-\rho t) d t,
$$

subject to each flow budget equation and asset constraint:

$$
\begin{gathered}
\dot{a}=r a+w x-c-R m-z, \quad \dot{a}^{*}=r a^{*}+w^{*} x^{*}-c^{*}-R^{*} m^{*}-z^{*}, \\
a=m+b, \quad a^{*}=m^{*}+b^{*},
\end{gathered}
$$

where $w$ (or $w^{*}$ ) is the real wage, $z$ (or $z^{*}$ ) is the lump-sum tax, and $x$ (or $x^{*}$ ) is employment. Real total assets $a$ (or $a^{*}$ ) consist of real money balances $m$ (or $m^{*}$ ) and foreign asset $b$ (or $b^{*}$ ) while the firm value is zero under the linear technology. The real rate of interest $r$ is internationally the same, as shown by (3). The two countries' labor endowments are normalized to 1 and may not be fully employed. Therefore, each country’s actual employment $x\left(\right.$ or $\left.x^{*}\right)$ implies each employment rate. 
From the Hamiltonian function of each household's optimization behavior:

$$
\begin{gathered}
H=u(c)+v(m)+\lambda(r a+w x-c-R m-z), \\
H^{*}=u\left(c^{*}\right)+v\left(m^{*}\right)+\lambda^{*}\left(r a^{*}+w^{*} x^{*}-c^{*}-R^{*} m^{*}-z^{*}\right),
\end{gathered}
$$

one obtains the first-order optimal conditions: $:^{5}$

$$
\begin{gathered}
\lambda=u^{\prime}(c), \quad \lambda R=v^{\prime}(m), \quad \frac{\dot{\lambda}}{\lambda}=\rho-r, \\
\lambda^{*}=u^{\prime}\left(c^{*}\right), \quad \lambda^{*} R^{*}=v^{\prime}\left(m^{*}\right), \quad \frac{\lambda^{*}}{\lambda^{*}}=\rho-r .
\end{gathered}
$$

From the Ramsey equations in (6), one finds

$$
\lambda^{*}=\kappa \lambda, \quad \kappa=\text { constant over time. }
$$

From (3), (6) and (7), world total consumption $D$ satisfies

$$
\begin{gathered}
D(=c+c *)=u^{\prime-1}(\lambda)+u^{\prime-1}(\kappa \lambda) \rightarrow \lambda=\lambda(D, \kappa), \\
\left(\frac{\lambda_{D} D}{\lambda}\right) \frac{\dot{D}}{D}=\rho+\pi-\frac{v^{\prime}(m)}{u^{\prime}(c)},
\end{gathered}
$$

where $\lambda$ satisfies

$$
\begin{gathered}
\frac{\lambda_{D}}{\lambda}=-1 /\left(\frac{c}{\eta}+\frac{c^{*}}{\eta^{*}}\right)<0, \quad \frac{\kappa \lambda_{\kappa}}{\lambda}=-\left(\frac{c^{*}}{\eta^{*}}\right) /\left(\frac{c}{\eta}+\frac{c^{*}}{\eta^{*}}\right)<0, \\
\eta=-\frac{u^{\prime \prime}(c) c}{u^{\prime}(c)}, \quad \eta^{*}=-\frac{u^{\prime \prime}\left(c^{*}\right) c^{*}}{u^{\prime}\left(c^{*}\right)},
\end{gathered}
$$

and $R$ and $R$ are

$$
R=\frac{v^{\prime}(m)}{u^{\prime}(c)}, \quad R^{*}=\frac{v^{\prime}\left(m^{*}\right)}{u^{\prime}\left(c^{*}\right)}
$$

The home (or foreign) government imposes lump-sum tax $z$ (or $z^{*}$ ) and purchases commodity $i(i=1,2)$ by the amount of $g_{i}\left(\right.$ or $\left.g_{i}^{*}\right)$. Therefore,

$$
z=p_{1}(\omega) g_{1}+p_{2}(\omega) g_{2}, \quad z^{*}=p_{1}(\omega) g_{1}^{*}+p_{2}(\omega) g_{2}^{*}
$$

${ }^{5}$ Apparently, by replacing $u(c)$ by $\hat{u}\left(c_{1}, c_{2}\right)$ one obtains the intratemporal and intertemporal optimal conditions given by (1) and (6) all at once. 
From the home and foreign demand functions presented by (1), the world demand for commodity 1 and that for commodity 2 are $\delta(\omega) D / p_{1}(\omega)$ and $[1-\delta(\omega)] D / p_{2}(\omega)$, respectively. Commodity prices perfectly adjust in the international competitive market so that

$$
\begin{gathered}
\frac{\delta(\omega)}{p_{1}(\omega)} D+g_{1}+g_{1}^{*}=\theta_{1} x, \\
\frac{1-\delta(\omega)}{p_{2}(\omega)} D+g_{2}+g_{2}^{*}=\theta_{2}^{*} x^{*},
\end{gathered}
$$

where $\theta_{1}$ is the home productivity and $\theta_{2}^{*}$ is the foreign productivity. Real balances $m$ and $m^{*}$ satisfy

$$
m=\frac{M}{P}, \quad m^{*}=\frac{M^{*}}{P^{*}}
$$

where $M$ and $M^{*}$ are nominal money supplies. It is assumed that $M$ and $M^{*}$ are constant over time while they may increase in a once-and-for-all manner. Because the above equations yield

$$
\dot{m}=-\pi m, \quad \dot{m}^{*}=-\pi^{*} m^{*}
$$

and $z$ and $z^{*}$ satisfy (11), the flow budget equations in (5) reduce to

$$
\begin{gathered}
\dot{b}=r b+p_{1}(\omega) \theta_{1} x-c-\left[p_{1}(\omega) g_{1}+p_{2}(\omega) g_{2}\right], \\
\dot{b}^{*}=r b^{*}+p_{2}(\omega) \theta_{2}^{*} x^{*}-c^{*}-\left[p_{1}(\omega) g_{1}^{*}+p_{2}(\omega) g_{2}^{*}\right] .
\end{gathered}
$$

Foreign assets $b$ and $b^{*}$ always satisfy

$$
b+b^{*}=0 \text {. }
$$

\section{The condition for the asymmetric steady state to arise}

This section presents the condition for the asymmetric case to appear, in which the home country faces persistent unemployment while the foreign country achieves full employment. Dynamics and stability are examined in the next section.

When a steady state is reached, $c$ and $c^{*}$ are constant and hence from (6) and (13),

$$
\rho=\frac{v^{\prime}(M / P)}{u^{\prime}(c)}, \quad \rho=\frac{v^{\prime}\left(M^{*} / P^{*}\right)}{u^{\prime}\left(c^{*}\right)} .
$$


Current accounts $\dot{b}$ and $\dot{b}^{*}$ given in (14) are zero. Therefore, if both countries achieve full employment, i.e.,

$$
x=1, \quad x^{*}=1
$$

from (14) and (15) $c$ and $c^{*}$ are

$$
\begin{gathered}
c=c_{f} \equiv \rho b+p_{1}\left(\omega^{f}\right) \theta_{1}-\left[p_{1}\left(\omega^{f}\right) g_{1}+p_{2}\left(\omega^{f}\right) g_{2}\right], \\
c^{*}=c_{f}^{*} \equiv-\rho b+p_{2}\left(\omega^{f}\right) \theta_{2}^{*}-\left[p_{1}\left(\omega^{f}\right) g_{1}^{*}+p_{2}\left(\omega^{f}\right) g_{2}^{*}\right],
\end{gathered}
$$

where $\omega^{f}$ satisfies (12) in which $x=1$ and $x^{*}=1$, and hence

$$
\frac{\omega^{f} \delta\left(\omega^{f}\right)}{1-\delta\left(\omega^{f}\right)}=\frac{\theta_{1}-g_{1}-g_{1}^{*}}{\theta_{2}^{*}-g_{2}-g_{2}^{*}}
$$

Substituting these $c$ and $c^{*}$ into (16) gives the steady state levels of $P$ and $P^{*}$.

However, in the presence of a liquidity trap the steady state presented above may not exist. In the present setting a liquidity trap emerges if the marginal utility of money $v^{\prime}(m)$ has a positive lower bound $\beta,{ }^{6}$

$$
\lim _{m \rightarrow \infty} v^{\prime}(m)=\beta>0,
$$

because the first two equations in (6) gives the home money demand function:

$$
R=\frac{v^{\prime}(m)}{u^{\prime}(c)}\left(>\frac{\beta}{u^{\prime}(c)} \text { for any } m\right)
$$

and with (18) $R$ stays strictly positive as $m$ increases, implying a liquidity trap. ${ }^{7}$ In this case, if and only if $c_{f}$, the home consumption under full employment given in (17), is so large as to satisfy

$$
\rho<\frac{\beta}{u^{\prime}\left(c_{f}\right)}\left(<\frac{v^{\prime}(M / P)}{u^{\prime}\left(c_{f}\right)} \text { for any } P\right)
$$

${ }^{6}$ Ono (1994, 2001) assumes this property in a closed-economy setting and proves that the dynamic equilibrium path uniquely exists and converges to a steady state with persistent unemployment. The validity of this property is empirically shown by Ono, Ogawa and Yoshida (2004) using both a parametric and a non-parametric approach.

${ }^{7}$ If $v^{\prime}(m)$ remains positive as $m$ expands, $v(m)$ may not represent the transaction motive. It would rather imply wealth preference. In Appendix A this is taken into account and wealth preference and the narrowly-defined transaction motive are separately introduced to the present model. It is shown that the following analysis is still valid and that the home nominal interest rate is zero in the steady state. 
there is no $P$ that makes the first equation in (16) valid. Therefore, there is no dynamic path along which full employment is reached in the home country. Given that the left- and right-hand sides of (19) respectively represent the time preference rate and the liquidity premium, (19) shows the case where the marginal desire for holding money dominates that for consumption if the household consumes enough to realize full employment. The same argument applies to the foreign country.

If the home country cannot reach full employment while the foreign country can in the steady state, (19) is valid in the home country while foreign full-employment consumption $c_{f}^{*}$ given in (17) satisfies

$$
\rho>\frac{\beta}{u^{\prime}\left(c_{f}^{*}\right)}
$$

so that there is $P^{*}$ that satisfies the second equation of (16). From (17), (19) and the above inequality, the asymmetric case emerges when ${ }^{8}$

$$
\begin{gathered}
\rho<\frac{\beta}{u^{\prime}\left(\rho b+p_{1}\left(\omega^{f}\right) \theta_{1}-\left[p_{1}\left(\omega^{f}\right) g_{1}+p_{2}\left(\omega^{f}\right) g_{2}\right]\right)}, \\
\rho>\frac{\beta}{u^{\prime}\left(-\rho b+p_{2}\left(\omega^{f}\right) \theta_{2}^{*}-\left[p_{1}\left(\omega^{f}\right) g_{1}^{*}+p_{2}\left(\omega^{f}\right) g_{2}^{*}\right]\right)} .
\end{gathered}
$$

From these conditions one finds that the asymmetric case in which $g_{i}^{(*)}=0$ (for $i=1,2$ ) appears if

$$
\rho b>\max \left(u^{\prime-1}\left(\frac{\beta}{\rho}\right)-p_{1}\left(\omega^{f}\right) \theta_{1},-u^{\prime-1}\left(\frac{\beta}{\rho}\right)+p_{2}\left(\omega^{f}\right) \theta_{2}^{*}\right)
$$

This is valid when home productivity $\theta_{1}$ is high while foreign productivity $\theta_{2}^{*}$ is low and when the home country owns huge foreign assets (i.e., $b$ is large). It may be plausible when the home country is developed and the foreign country is emerging. In the following analysis this case is considered.

\footnotetext{
${ }^{8}$ Ono (2014) deals with the case where the first inequality is valid but the second one is not, that is, the case where neither country has a full-employment steady state.
} 


\section{Dynamics and local stability}

In the asymmetric case the home country cannot reach full employment. In order to deal with this case, therefore, sluggish wage adjustments in the presence of labor demand shortages must be introduced. The dominant setting of price and wage adjustments in DSGE models is that of Calvo (1983). However, it does not suit the present analysis because it allows neither aggregate demand shortages nor unemployment any time. Aggregate demand shortages are explicitly analyzed by Krugman (1998) in a discrete-time setting. However, it cannot treat long-run unemployment because the length of each period is exogenously given and a demand shortage appears only in the period in which an exogenous shock occurs. In contrast, a dynamic extension of Akerlof's fair wage model (1982), presented by Ono and Ishida (2014), can deal with unemployment as well as full employment during the adjustment process and in the steady state. Therefore, it is adopted in the following analysis.

\subsection{Wage and price adjustments}

In each country there are three kinds of workers, employed, unemployed and newly hired ones. The employed randomly separate from the current job at an exogenously given Poison rate $\alpha \cdot{ }^{9}$ Therefore, employment $x$ follows

$$
\dot{x}=-\alpha x+\chi,
$$

where $\chi$ is the number of the newly hired. While workers are employed, they form fair wages in mind by referring to their past wages, their fellow workers' fair wages (which eventually equal their own fair wages) and the unemployment level of the society. More precisely, at the

\footnotetext{
${ }^{9}$ The Calvo model also assumes an exogenous Poison rate at which a firm (or a labor union) has a chance of revising prices (or wages) at each time point. The present $\alpha$ instead represents a timing of revising the fair wage because some of the incumbent workers that conceive fair wages leave the job, as mentioned later.
} 
end of the previous period ( $t-\Delta t$ ) each employed worker conceives the rightful wage $v(t-\Delta t)$, which is the wage that he or she believes fair if full employment prevails. Next, he or she calculates the average of the rightful wages of the employed, which are the same to each other, and the income of the unemployed, which is assumed to be zero for simplicity. The average is taken as the fair wage $W_{F}(t)$.

Because the numbers of the employed and the unemployed are respectively $x(t-\Delta t)$ and $1-x(t-\Delta t)$, the employed calculate the rightful wage $v(t-\Delta t)$ from

$$
v(t-\Delta t) x(t-\Delta t)+0 \times[1-x(t-\Delta t)]=W_{F}(t-\Delta t),
$$

at the timing denoted by $(\mathrm{A})$ in figure 1 . The newly hired, in contrast, have no preconception about the fair wage or the rightful wage and simply follow the fair wage of the employed. Therefore, when the employed calculate the fair wage $W_{F}(t)$ at time $t$, the total number of workers that they care is $1-\chi(t) \Delta t$ because the number of the newly hired is $\chi(t) \Delta t$. Because the number of the employed is $x(t-\Delta t)(1-\alpha \Delta t)$ at the timing denoted by (B) in figure 1 , the fair wage $W_{F}(t)$ turns out to be

$$
W_{F}(t)=\frac{v(t-\Delta t) x(t-\Delta t)(1-\alpha \Delta t)}{1-\chi(t) \Delta t} .
$$

From (22) and the above equation, one obtains

$$
\frac{W_{F}(t)-W_{F}(t-\Delta t)}{\Delta t}=\chi(t) W_{F}(t)-\alpha W_{F}(t-\Delta t) .
$$

Reducing $\Delta t$ to zero yields the dynamics of $W_{F}$ :

$$
\frac{\dot{W}_{F}}{W_{F}}=\chi-\alpha,
$$

implying that the fair wage is updated at the replacement pace of the employed.

If there is unemployment in the home country, the firm will set wage $W$ equal to fair wage $W_{F}$ because $W_{F}$ is the lowest wage under which the employees properly work. The commodity price $P_{1}$ adjusts to $W_{F} / \theta_{1}$ since there is no commodity supply if $P_{1}<W_{F} / \theta_{1}$ and excess commodity supply if $P_{1}>W_{F} / \theta_{1}$. If full employment prevails, in contrast, the firm tries to 
pick out workers from rival firms to expand the market share by increasing $W$ from $W_{F}$ so long as the marginal profits are positive. Therefore, $W$ is higher than the fair wage $W_{F}$ that follows (23), and is equalized to $\theta_{1} P_{1}$. The same argument is valid in the foreign country.

Note that each commodity price, $P_{1}$ in the home country and $P_{2}^{*}$ in the foreign country, follows the movement of the fair wage $W_{F}$ when there is unemployment, and that $W$ follows the movement of each commodity price regardless of $W_{F}$ when full employment maintains. Thus, anyway one has

$$
w=\frac{W}{P_{1}}=\theta_{1}, \quad w^{*}=\frac{W^{*}}{P_{2}^{*}}=\theta_{2}^{*} .
$$

\subsection{Dynamics and the asymmetric steady state}

In the following the asymmetric case represented by (20) is considered and then:

$$
x<1, \quad x^{*}=1 .
$$

Therefore, $W=W_{F}$ that follows (23) in the home country while $W^{*}$ and $P_{2}^{*}$ always adjust so that full employment maintains in the foreign country. Having such price and wage adjustments in mind, from (2), (4), the second equation of (12) in which $x^{*}=1,(23)$ and (24), one obtains

$$
\begin{gathered}
\frac{\dot{W}}{W}=\frac{\dot{P}_{1}}{P_{1}}=\pi-(1-\delta) \frac{\dot{\omega}}{\omega}=\chi-\alpha . \\
\frac{1-\delta(\omega)}{p_{2}(\omega)} D+g_{2}+g_{2}^{*}=\theta_{2}^{*} \rightarrow \omega=\omega\left(D ; \theta_{2}^{*}-g_{2}-g_{2}^{*}\right) .
\end{gathered}
$$

Using (4), the time derivative of the first equation in (12) and that of the second equation in (25), one finds

$$
\begin{gathered}
\frac{\dot{\omega}}{\omega}=\left(\frac{1-\delta}{\delta(1-\delta)+\delta^{\prime} \omega}\right) \frac{\dot{D}}{D}, \\
\dot{x}=\left(\frac{D}{p_{1} \theta_{1}}\right) \frac{\dot{D}}{D} .
\end{gathered}
$$

Equation (21), the first equation of (25) and the two equations of (26) give 


$$
\pi=\alpha(x-1)+\left(\frac{D}{p_{1} \theta_{1}}+\frac{(1-\delta)^{2}}{\delta(1-\delta)+\omega \delta^{\prime}}\right) \frac{\dot{D}}{D}
$$

Note that the Poison rate of job separation $\alpha$ is to be the price adjustment speed around the steady state in which $D$ is constant and that $1 / \alpha$ denotes the average duration of employment.

Substituting $x$ obtained from the first equation of (12) into the above expression of $\pi$ and applying the result to $\pi$ in (8) leads to

$$
\left(\frac{D}{p_{1} \theta_{1}}+\frac{(1-\delta)^{2}}{\delta(1-\delta)+\omega \delta^{\prime}}-\frac{\lambda_{D} D}{\lambda}\right) \frac{\dot{D}}{D}=\frac{v^{\prime}(m)}{\lambda(C, \kappa)}-\rho-\alpha\left(\frac{\delta\left(\omega\left(D ; \theta_{2}^{*}-g_{2}-g_{2}^{*}\right)\right)}{p_{1}\left(\omega\left(D ; \theta_{2}^{*}-g_{2}-g_{2}^{*}\right)\right) \theta_{1}} D+\frac{g_{1}+g_{1}^{*}}{\theta_{1}}-1\right),
$$

where $\omega\left(D ; \theta_{2}^{*}-g_{2}-g_{2}^{*}\right)$ is given by the second equation of (25). From (1) and (9), the coefficient of $\dot{D} / D$ in (27) is positive. In the neighborhood of the steady state, deflation continues and $v^{\prime}(m)$ sticks to $\beta$, and hence the dynamic equation given by (27) reduces to

$$
\left(\frac{D}{p_{1} \theta_{1}}+\frac{(1-\delta)^{2}}{\delta(1-\delta)+\omega \delta^{\prime}}-\frac{\lambda_{D} D}{\lambda}\right) \frac{\dot{D}}{D}=\frac{\beta}{\lambda(D, \kappa)}-\rho-\alpha\left(\frac{\delta(\omega)}{p_{1}(\omega) \theta_{1}} D+\frac{g_{1}+g_{1}^{*}}{\theta_{1}}-1\right) \equiv \Delta(D, \kappa) .
$$

In Appendix B it is proven that if

$$
\rho-\alpha>0
$$

$D$ jumps to the level that makes $\Delta(D, \kappa)=0$ and the steady state is immediately reached, once $\kappa$ is given. ${ }^{10}$

Moreover, from (6) and (7), $\kappa$ must equal $u^{\prime}\left(c^{*}\right) / u^{\prime}(c)$ where $c$ and $c^{*}$ make $\dot{b}\left(=-\dot{b}^{*}\right)$ in (14) equal zero because otherwise $\dot{b}$ and $-\dot{b}^{*}$ continue to either expand or decline and the non-Ponzi game condition is violated. Therefore,

$$
\begin{gathered}
u^{\prime}\left(c^{*}\right)=\kappa u^{\prime}(c), \\
c=D-c^{*}, \\
c^{*}=-\rho b+p_{2}(\omega)\left(\theta_{2}^{*}-g_{2}^{*}\right)-p_{1}(\omega) g_{1}^{*},
\end{gathered}
$$

where $\omega$ satisfies the second equation of (25). This $\kappa$ depends on only $D$ besides exogenous parameters. By substituting this $\kappa$ into (28) and equalizing the result to zero,

\footnotetext{
${ }^{10}$ If the job-separation rate $\alpha$ is regarded as the rate of death as a worker, it is naturally less than the subjective discount rate $\rho$.
} 


$$
\begin{gathered}
\emptyset\left(D ; \alpha, \beta, b, g_{1}, g_{2}, \theta_{1}, g_{1}^{*}, \theta_{2}^{*}-g_{2}^{*}\right) \\
\equiv \frac{\beta}{\lambda(D, \kappa)}-\rho-\alpha\left(\frac{\delta\left(\omega\left(D ; \theta_{2}^{*}-g_{2}-g_{2}^{*}\right)\right)}{p_{1}\left(\omega\left(D ; \theta_{2}^{*}-g_{2}-g_{2}^{*}\right)\right) \theta_{1}} D+\frac{g_{1}+g_{1}^{*}}{\theta_{1}}-1\right)=0,
\end{gathered}
$$

one obtains the steady-state level of $D$. Substituting this $D$ to the second equation of (25) gives $\omega$, and hence from (30) $c^{*}$ and $c\left(=D-c^{*}\right)$ obtain.

Let us finally prove that this steady state indeed exists in the neighborhood where

$$
g_{1}=g_{1}^{*}=0, \quad g_{2}=g_{2}^{*}=0 .
$$

From (4), the second equation of (25) and the second and third equations of (30), one obtains

$$
\frac{d c}{d D}=\frac{\delta^{2}(1-\delta)+\omega \delta^{\prime}}{\delta(1-\delta)+\omega \delta^{\prime}}>0,
$$

i.e., the steady-state level of $c$ is larger as $D$ increases. If $D$ is small enough to make $c$ equal zero, $D=c^{*}$ and $\lambda=u^{\prime}(0)=\infty$. Thus, under (29) $\emptyset$ given by (31) satisfies

$$
\emptyset\left(c^{*} ; \ldots\right)=-\rho-\alpha\left(\frac{\delta(\omega) c^{*}}{p_{1}(\omega) \theta_{1}}-1\right)<0 .
$$

If $D$ is so large as to make $c$ equal the full-employment level $c_{f}$, from the first equation of (12) in which $x=1$, the third term of the right-hand side of (31) is zero. Thus, from (19) $\emptyset$ given by (31) satisfies

$$
\varnothing\left(D_{f} ; \ldots\right)=\frac{\beta}{u^{\prime}\left(c_{f}\right)}-\rho>0
$$

where $D_{f}$ is the level of $D$ that makes both countries attain full employment. These two properties guarantee the existence of $D$ that makes $\emptyset$ equal zero and $c$ locate within $\left(0, c_{f}\right)$. It also implies that around the steady state level of $D$

$$
\emptyset_{D}(D ; \ldots)>0
$$

\section{Own and spillover effects of policy and parameter changes}

This section analyzes the effects of changes in various policy, technological and preference parameters on the two countries' consumption $c$ and $c^{*}$. As shown in the previous 
section, after those parameters change, the new steady state is immediately reached. Therefore, one can obtain the effects on $c$ and $c^{*}$ of changes in the parameters by ignoring the transitional process and simply calculating the effects on their steady-state levels.

Totally differentiating (31) yields

$$
\begin{gathered}
\emptyset_{D} d D=-\emptyset_{\alpha} d \alpha-\emptyset_{\beta} d \beta-\emptyset_{b} d b-\emptyset_{g_{1}} d g_{1}-\emptyset_{g_{2}} d g_{2}-\emptyset_{\theta_{1}} d \theta_{1} \\
-\emptyset_{g_{1}^{*}} d g_{1}^{*}-\emptyset_{\theta_{2}^{*}-g_{2}^{*}} d\left(\theta_{2}^{*}-g_{2}^{*}\right) .
\end{gathered}
$$

As shown in Appendix C, the partial derivatives in the neighborhood of (32) are derived from (4), (9), (31) to which $\omega$ in the second equation of (25) and $\kappa$ in (30) are applied. Because $\emptyset_{D}$ in (34) is positive, as given in (33), and $0<\delta<1$ from (1), they satisfy

$$
\begin{gathered}
\emptyset_{D}=\left(\frac{\eta}{c}\right)\left(\frac{\beta}{\lambda}\right) \frac{\delta^{2}(1-\delta)+\omega \delta^{\prime}}{\delta(1-\delta)+\omega \delta^{\prime}}-\frac{\alpha}{p_{1} \theta_{1}}>0, \\
\emptyset_{\alpha}=1-x>0, \quad \emptyset_{\beta}=\frac{1}{\lambda}>0, \quad \emptyset_{b}=\rho\left(\frac{\eta}{c}\right)\left(\frac{\beta}{\lambda}\right)>0, \\
\emptyset_{g_{1}}=-\frac{\alpha}{\theta_{1}}<0, \quad \emptyset_{g_{2}}=-\left(\frac{\eta}{c}\right)\left(\frac{\beta}{\lambda}\right) \frac{p_{2} \delta(1-\delta)}{\delta(1-\delta)+\omega \delta^{\prime}}-\frac{\alpha \omega}{\theta_{1}}<0, \quad \emptyset_{\theta_{1}}=\frac{\alpha x}{\theta_{1}}>0, \\
\emptyset_{g_{1}^{*}}=\left(\frac{\eta}{c}\right)\left(\frac{\beta}{\lambda}\right) p_{1}-\frac{\alpha}{\theta_{1}}>0, \quad \emptyset_{\theta_{2}^{*}-g_{2}^{*}}=-p_{2}\left[\left(\frac{\eta}{c}\right)\left(\frac{\beta}{\lambda}\right) \frac{\omega \delta^{\prime}}{\delta(1-\delta)+\omega \delta^{\prime}}-\frac{\alpha}{p_{1} \theta_{1}}\right] .
\end{gathered}
$$

In Appendix $C d c^{*}$ and $d c\left(=d D-d c^{*}\right)$ are derived from the second equation of (25), the third equation of (30), (34) and (35). They are

$$
\begin{gathered}
\emptyset_{D} d c=-\frac{\rho \alpha}{p_{1} \theta_{1}} d b-\frac{\delta^{2}(1-\delta)+\omega \delta^{\prime}}{\delta(1-\delta)+\omega \delta^{\prime}}\left[\emptyset_{\alpha} d \alpha+\emptyset_{\beta} d \beta+\emptyset_{g_{1}} d g_{1}+\emptyset_{\theta_{1}} d \theta_{1}\right] \\
+\left(\frac{\alpha}{p_{1} \theta_{1}}\right) \frac{\delta\left(1-\delta^{2}\right)+\omega \delta^{\prime}}{\delta(1-\delta)+\omega \delta^{\prime}} p_{2} d g_{2}-\left(\frac{\alpha}{\theta_{1}}\right) \frac{\delta(1-\delta)^{2}}{\delta(1-\delta)+\omega \delta^{\prime}} d g_{1}^{*} \\
-\left(\frac{\alpha}{p_{1} \theta_{1}}\right) \frac{\delta^{2}(1-\delta)}{\delta(1-\delta)+\omega \delta^{\prime}} p_{2} d\left(\theta_{2}^{*}-g_{2}^{*}\right), \\
\emptyset_{D} d c^{*}=-\rho\left[\left(\frac{\eta}{c}\right)\left(\frac{\beta}{\lambda}\right)-\frac{\alpha}{p_{1} \theta_{1}}\right] d b-\frac{\delta(1-\delta)^{2}}{\delta(1-\delta)+\omega \delta^{\prime}}\left[\emptyset_{\alpha} d \alpha+\emptyset_{\beta} d \beta+\emptyset_{g_{1}} d g_{1}+\emptyset_{\theta_{1}} d \theta_{1}\right] \\
+\left(\frac{\delta(1-\delta)}{\delta(1-\delta)+\omega \delta^{\prime}}\right)\left[\left(\frac{\eta}{c}\right)\left(\frac{\beta}{\lambda}\right)-\frac{\delta \alpha}{p_{1} \theta_{1}}\right] p_{2} d g_{2}-\left[p_{1} \emptyset_{D}+\frac{\delta(1-\delta)^{2}}{\delta(1-\delta)+\omega \delta^{\prime}} \emptyset_{g_{1}^{*}}\right] d g_{1}^{*} \\
+\left[\left(\frac{\eta}{c}\right)\left(\frac{\beta}{\lambda}\right) \frac{\omega \delta^{\prime}}{\delta(1-\delta)+\omega \delta^{\prime}}-\left(\frac{\alpha}{p_{1} \theta_{1}}\right) \frac{\delta(1-\delta)^{2}+\omega \delta^{\prime}}{\delta(1-\delta)+\omega \delta^{\prime}}\right] p_{2} d\left(\theta_{2}^{*}-g_{2}^{*}\right) .
\end{gathered}
$$


Note that the coefficient of $d b$ in (37) is negative while that of $d g_{2}$ in (37) is positive because $\emptyset_{D}$ in (35) is positive and $0<\delta<1$ from (1). The signs of the other coefficients in (36) and (37), except that of $d\left(\theta_{2}^{*}-g_{2}^{*}\right)$ in (37), are clear. Therefore, one finds

$$
\begin{gathered}
\alpha \downarrow, \beta \downarrow, b \downarrow, g_{1} \uparrow, g_{2} \uparrow, \theta_{1} \downarrow, g_{1}^{*} \downarrow \Rightarrow c \uparrow, c^{*} \uparrow, \\
\theta_{2}^{*}-g_{2}^{*} \uparrow \Rightarrow c \downarrow, \quad c^{*} \uparrow \downarrow .
\end{gathered}
$$

From the second equation of (25),

$$
\begin{gathered}
d \omega=\omega_{D} d D+\omega_{\theta_{2}^{*}-g_{2}-g_{2}^{*}} d\left(\theta_{2}^{*}-g_{2}-g_{2}^{*}\right), \\
\left(\frac{D}{\omega}\right) \omega_{D}=\frac{1-\delta}{\delta(1-\delta)+\omega \delta^{\prime}}>0, \quad\left(\frac{D}{\omega}\right) \omega_{\theta_{2}^{*}-g_{2}-g_{2}^{*}}=-\frac{p_{2}}{\delta(1-\delta)+\omega \delta^{\prime}}<0 .
\end{gathered}
$$

From (34) and the above equations, the effect on $\omega$ of a change in $\theta_{2}^{*}-g_{2}^{*}$ is

$$
\left(\frac{D \emptyset_{D}}{\omega}\right) \frac{d \omega}{d\left(\theta_{2}^{*}-g_{2}^{*}\right)}=-\left(\frac{\delta p_{2}}{\delta(1-\delta)+\omega \delta^{\prime}}\right)\left[\left(\frac{\eta}{c}\right)\left(\frac{\beta}{\lambda}\right)-\frac{\alpha}{p_{1} \theta_{1}}\right]<0 .
$$

These properties and (35) give

$$
\alpha \downarrow, \beta \downarrow, b \downarrow, g_{1} \uparrow, g_{2} \uparrow, \theta_{1} \downarrow, g_{1}^{*} \downarrow, \theta_{2}^{*}-g_{2}^{*} \downarrow \Rightarrow \omega \uparrow .
$$

Let us discuss the implication of the main results summarized in (38) and (39). When the home country suffers persistent unemployment, a decrease in the Poison rate of job separation $\alpha$ (or an increase in the average duration of employment $1 / \alpha$ ) alleviates deflation in the home country. Therefore, it makes more advantageous for home households to consume than to hold money and hence stimulates home consumption. Consequently, the current account worsens and the home currency depreciates, which improves the competitiveness of home firms and expands employment, further alleviating deflation. The home-currency depreciation in turn improves the terms of trade for the foreign country and makes it better off because full employment prevails in the foreign country.

A decrease in the liquidity preference parameter $\beta$ stimulates home consumption and moderates deflation, which further stimulates consumption. It expands imports, worsens the current account, depreciates the home currency, makes home firms more competitive and 
expands home employment. The foreign country is also better off because the depreciation of the home currency improves the foreign terms of trade. An expansion in $g_{1}$, home government purchases on the home commodity, creates new home employment and reduces the deflationary gap. Therefore, the same positive effects as those of a decrease in $\beta$ emerge. An improvement in home productivity $\theta_{1}$, in contrast, widens the deflationary gap, which reduces home consumption, and hence the opposite effects arise in both countries. Home employment shrinks so much as to dominate the initial improvement in $\theta_{1}$ and the foreign terms of trade worsens, which makes both countries worse off.

A transfer from the home country to the foreign country lowers the home foreign-asset position $b$ and thereby worsens the home current account. It causes the home currency to depreciate and increases home production, employment and consumption. Consequently, the home country is better off. The foreign country is also better off because it not only receives the transfer but also benefits from the improvement in the terms of trade. This result may be consistent with the consequence of the Marshall Plan and the statement of the Brandt commission, both mentioned in the introduction.

An expansion in $g_{2}$, home government purchases on the foreign commodity, worsens the home current account and makes the home currency depreciate. Therefore, home firms become more competitive and increase employment, which alleviates deflation and stimulates home consumption. The foreign country is also better off because of the improvement in the terms of trade. An increase in $g_{1}^{*}$, foreign government purchases on the home commodity, works in the opposite direction. It improves the home current account, which makes the home currency appreciate and the real price of the home commodity $\left(p_{1}\right)$ increase. Even if the home currency appreciates so much that home employment $x$ and home consumption $c$ return to the previous levels, the current account is still positive because $p_{1}$ is higher than before. Therefore, the home currency further appreciates and eventually makes $x$ and $c$ lower than the previous 
levels, harming the home country. The foreign country is also harmed because under full employment not only an increase in government purchases crowds out private consumption but also the terms of trade worsens.

The above argument may be summarized as follows. If the home country suffers long-run deficiency of aggregate demand and the foreign country achieves full employment, a parameter or policy change that worsens the home current account generally depreciates the home currency, stimulates home production and employment, mitigates deflation and hence stimulates home consumption. The depreciation of the home currency improves the foreign terms of trade and hence benefits the foreign country.

An increase in $g_{2}^{*}$, foreign government purchases on the foreign commodity, raises the relative price of the foreign commodity, which expands home employment and stimulates home consumption. The rise in the foreign commodity price benefits the foreign country. However, it is caused by an increase in foreign government purchases on the foreign commodity, which harms the foreign country. Therefore, the welfare effect on foreign households is ambiguous while the home country benefits. The effect of an increase in foreign productivity $\theta_{2}^{*}$ is just the opposite.

\section{Conclusions}

A two-country economy in which the home country suffers persistent unemployment due to aggregate demand deficiency while the foreign country realizes full employment is considered. The stagnant country often attempts to improve production efficiency, expecting that such an effort would expand the world market share of home commodities and increase national income. However, it improves the current account and thereby appreciates the home currency. In the presence of aggregate demand deficiency the appreciation of the home 
currency is so high that employment eventually decreases and national income and consumption decline, making the home country worse off. It also worsens the foreign terms of trade and harms the foreign country with full employment.

In contrast, the home country's changes in policy and preference parameters that worsen the home current account cause the home currency to depreciate and thereby expand home employment and consumption. It also improves the foreign terms of trade and makes the foreign country better off. Typical examples are expansions of home government purchases on home and foreign commodities.

Foreign aid may be another important example. Foreign aid expenditures tend to be cut when a donor country suffers long-run stagnation. However, an expansion in foreign aid in fact makes the country better off because it worsens the home current account, depreciates the home currency, stimulates business, increases home employment, decreases deflation, and urges people to consume more. Moreover, if the recipient country is fully employed, it is also better off because it not only receives foreign aid but also benefits from the improvement in the terms of trade. 


\section{Appendices}

\section{Appendix A: Wealth preference and zero interest rate}

In the text $v^{\prime}(m)$ is assumed to have a positive lower bound. This property would rather imply wealth preference than liquidity preference. Moreover, from (10) the nominal interest rate is $v^{\prime}(m) / u^{\prime}(c)$, which converges to $\beta / u^{\prime}(c)(>0)$ in the asymmetric steady state, while the observed rate in a stagnant economy, such as Japan, is almost zero. This appendix explicitly separates liquidity preference and wealth preference and shows that the result in the text still holds while the nominal interest rate is zero.

If wealth preference $\varphi(a)$ is considered, the home utility is

$$
\int_{0}^{\infty}[u(c)+v(m)+\varphi(a)] \exp (-\rho t) d t
$$

in which $v(m)$ now represents the transaction motive and satisfies

$$
\lim _{m \rightarrow \infty} v^{\prime}(m)=0 .
$$

In this case the first-order optimal conditions of the home household in (6) are replaced by

$$
\lambda=u^{\prime}(c), \quad \lambda R=v^{\prime}(m), \quad \frac{\dot{\lambda}}{\lambda}=\rho-r-\frac{\varphi^{\prime}(a)}{u^{\prime}(c)} .
$$

Therefore, (8) turns to be

$$
\rho+\pi-\left(\frac{\lambda_{D} D}{\lambda}\right) \frac{\dot{D}}{D}-=\frac{v^{\prime}(m)+\varphi^{\prime}(a)}{u^{\prime}(c)},
$$

while (10) is unchanged; that is,

$$
R=\frac{v^{\prime}(m)}{u^{\prime}(c)}
$$

Because all the other equations in the text are unchanged, by replacing $v^{\prime}(m)$ with $v^{\prime}(m)+$ $\varphi^{\prime}(a)$ one obtains the same dynamic equations.

In the symmetric steady state deflation continues in the home country and $m$ continues to expand. Therefore, from (A1) and (A2), one finds

$$
R=\lim _{m \rightarrow \infty} \frac{v^{\prime}(m)}{u^{\prime}(c)}=0,
$$


implying that the nominal interest rate observed in the home country is zero. Furthermore, by assuming that

$$
\lim _{a \rightarrow \infty} \varphi^{\prime}(a)=\beta_{a}>0,
$$

instead of (18), one obtains the same steady-state condition as (31) in which $\beta$ is replaced by $\beta_{a}$. Therefore, all the results of policy and parameter changes in the text are valid, while the home nominal interest rate is zero.

\section{Appendix B: Existence and stability of the dynamics represented by (28)}

If $D$ equals $D_{f}$ and the home country faces full employment, the first equation of (12) turns to be

$$
\delta(\omega) D_{f}+g_{1}+g_{1}^{*}=p_{1}(\omega) \theta_{1}
$$

Then, from (6), (8) and (19),

$$
\rho<\frac{\beta}{u^{\prime}\left(c_{f}\right)}=\frac{\beta}{\lambda\left(D_{f}, \kappa\right)},
$$

and $\Delta(D, \kappa)$ defined by (28) satisfies

$$
\Delta\left(D_{f}, \kappa\right)>0
$$

Therefore, in order for the steady-state level of $D$ to exist in the range of $\left(0, D_{f}\right)$, one must have

$$
\Delta(0, \kappa)<0
$$

Because $c=0$ if $D=0$ for a given $\kappa$, as is seen from (6), (7) and (8), $\lambda(0, \kappa)=u^{\prime}(0)=\infty$. Therefore, from (28), in the neighborhood where $g_{1}+g_{1}^{*}=0$ the above condition reduces to

$$
\rho-\alpha>0
$$

which is (29). Figure 2 illustrates this case - i.e., $R_{m}\left(=\beta / \lambda\left(D_{f}, \kappa\right)\right)$ is located above $\rho$ and $\rho-\alpha>0$.

In this case $\Delta(D, \kappa)$ must be positively inclines as $D$ increases around the steady state, $\mathrm{E}$ in the figure, and thus 


$$
\Delta_{D}(D, \kappa)>0
$$

Therefore, once $\kappa$ is given, $D$ jumps to the level that satisfies

$$
\Delta(D, \kappa)=0
$$

and the steady state of (28) is immediately reached.

\section{Appendix C: Derivations of (35), (36) and (37)}

From the first two equations of (30) one obtains

$$
u^{\prime \prime}\left(c^{*}\right) d c^{*}=\kappa u^{\prime \prime}(c)\left(d D-d c^{*}\right)+u^{\prime}(c) d \kappa .
$$

Substituting $\kappa$ given by the first equation of (30) into the above equation and utilizing $\eta$ and $\eta^{*}$ defined in (9) leads to

$$
\frac{d \kappa}{\kappa}=\frac{\eta}{c} d D-\left(\frac{\eta}{c}+\frac{\eta^{*}}{c^{*}}\right) d c^{*}
$$

From the third equation of (30), $d c^{*}$ is

$$
d c^{*}=-\rho d b+p_{2}^{\prime} \theta_{2}^{*} d \omega-p_{1} d g_{1}^{*}+p_{2} d\left(\theta_{2}^{*}-g_{2}^{*}\right),
$$

in the neighborhood of (32), that is, $g_{1}^{*}=0$ and $g_{2}^{*}=0$. Substituting (A4) into (A3) gives

$$
\frac{d \kappa}{\kappa}=\frac{\eta}{c} d D-\left(\frac{\eta}{c}+\frac{\eta^{*}}{c^{*}}\right)\left[-\rho d b+p_{2}^{\prime} \theta_{2}^{*} d \omega-p_{1} d g_{1}^{*}+p_{2} d\left(\theta_{2}^{*}-g_{2}^{*}\right)\right] .
$$

Totally differentiating the second equation of (25), substituting $\delta=\omega p_{2}^{\prime} / p_{2}$ given in (4) to the result and rearranging it yields

$$
D d \omega=\left(\frac{\omega}{\delta(1-\delta)+\omega \delta^{\prime}}\right)\left[(1-\delta) d D-p_{2} d\left(\theta_{2}^{*}-g_{2}^{*}-g_{2}\right)\right] .
$$

Substituting (A6) into (A5), and applying $\delta=\omega p_{2}^{\prime} / p_{2}$ given in (4) and $(1-\delta) D=p_{2} \theta_{2}^{*}$, obtained from the second equation of (25) and (32), to the result leads to

$$
\begin{gathered}
\frac{d \kappa}{\kappa}=\frac{\eta}{c} d D-\left(\frac{\eta}{c}+\frac{\eta^{*}}{c^{*}}\right)\left[\left(\frac{\delta(1-\delta)^{2}}{\delta(1-\delta)+\omega \delta^{\prime}}\right) d D-\rho d b+\left(\frac{\omega \delta^{\prime}}{\delta(1-\delta)+\omega \delta^{\prime}}\right) p_{2} d\left(\theta_{2}^{*}-g_{2}^{*}\right)\right. \\
\left.+\left(\frac{\delta(1-\delta)}{\delta(1-\delta)+\omega \delta^{\prime}}\right) p_{2} d g_{2}-p_{1} d g_{1}^{*}\right] .
\end{gathered}
$$

Totally differentiating (31) results in 


$$
\begin{gathered}
d \emptyset=\frac{d \beta}{\lambda}-\left(\frac{\beta}{\lambda}\right)\left(\frac{\lambda_{D}}{\lambda} d D+\frac{\lambda_{\kappa}}{\lambda} d \kappa\right)-(x-1) d \alpha \\
-\alpha\left[\frac{\delta}{p_{1} \theta_{1}} d D-\frac{\delta D}{p_{1} \theta_{1}}\left(\frac{d \theta_{1}}{\theta_{1}}\right)+\frac{D\left(\delta^{\prime}-\delta p_{1}^{\prime} / p_{1}\right)}{p_{1} \theta_{1}} d \omega+\frac{d g_{1}+d g_{1}^{*}}{\theta_{1}}\right]
\end{gathered}
$$

where $x$ is given by the first equation of (12). Substituting $\lambda_{D}$ and $\lambda_{\kappa}$ in (9) and $p_{1}^{\prime}$ in (4) to the above equation gives

$$
\begin{gathered}
d \varnothing=\frac{d \beta}{\lambda}+\left(\frac{\beta}{\lambda\left(\frac{c}{\eta}+\frac{c^{*}}{\eta^{*}}\right)}\right)\left[d D+\left(\frac{c^{*}}{\eta^{*}}\right) \frac{d \kappa}{\kappa}\right]-(x-1) d \alpha \\
-\alpha\left[\frac{\delta}{p_{1} \theta_{1}} d D-\frac{\delta D}{p_{1} \theta_{1}}\left(\frac{d \theta_{1}}{\theta_{1}}\right)+\frac{\delta(1-\delta)+\omega \delta^{\prime}}{p_{1} \theta_{1} \omega} D d \omega+\frac{d g_{1}+d g_{1}^{*}}{\theta_{1}}\right] .
\end{gathered}
$$

By substituting (A6) and (A7) to the above equation one obtains

$$
\begin{gathered}
d \varnothing=\frac{d \beta}{\lambda}-(x-1) d \alpha-\alpha\left[\frac{\delta}{p_{1} \theta_{1}} d D-\frac{\delta D}{p_{1} \theta_{1}}\left(\frac{d \theta_{1}}{\theta_{1}}\right)+\frac{(1-\delta) d D-p_{2} d\left(\theta_{2}^{*}-g_{2}^{*}-g_{2}\right)}{p_{1} \theta_{1}}+\frac{d g_{1}+d g_{1}^{*}}{\theta_{1}}\right] \\
+\left(\frac{\beta}{\lambda}\right)\left(\frac{\eta}{c}\right)\left[d D-\left(\frac{\delta(1-\delta)^{2}}{\delta(1-\delta)+\omega \delta^{\prime}}\right) d D+\rho d b-\left(\frac{\omega \delta^{\prime}}{\delta(1-\delta)+\omega \delta^{\prime}}\right) p_{2} d\left(\theta_{2}^{*}-g_{2}^{*}\right)\right. \\
\left.-\left(\frac{\delta(1-\delta)}{\delta(1-\delta)+\omega \delta^{\prime}}\right) p_{2} d g_{2}+p_{1} d g_{1}^{*}\right] .
\end{gathered}
$$

Rearranging this equation and applying the first equation of (12) and (32) to the result yields

$$
\begin{gathered}
d \emptyset=\frac{d \beta}{\lambda}-(x-1) d \alpha+\left[\left(\frac{\beta}{\lambda}\right)\left(\frac{\eta}{c}\right)\left(\frac{\delta^{2}(1-\delta)+\omega \delta^{\prime}}{\delta(1-\delta)+\omega \delta^{\prime}}\right)-\frac{\alpha}{p_{1} \theta_{1}}\right] d D+\frac{\alpha x}{\theta_{1}} d \theta_{1}+\rho\left(\frac{\beta}{\lambda}\right)\left(\frac{\eta}{c}\right) d b \\
-\frac{\alpha}{\theta_{1}} d g_{1}-\left[\left(\frac{\beta}{\lambda}\right)\left(\frac{\eta}{c}\right)\left(\frac{\delta(1-\delta)}{\delta(1-\delta)+\omega \delta^{\prime}}\right)+\frac{\alpha}{p_{1} \theta_{1}}\right] p_{2} d g_{2}+\left[\left(\frac{\beta}{\lambda}\right)\left(\frac{\eta}{c}\right) p_{1}-\frac{\alpha}{\theta_{1}}\right] d g_{1}^{*} \\
-\left[\left(\frac{\beta}{\lambda}\right)\left(\frac{\eta}{c}\right)\left(\frac{\omega \delta^{\prime}}{\delta(1-\delta)+\omega \delta^{\prime}}\right)-\frac{\alpha}{p_{1} \theta_{1}}\right] p_{2} d\left(\theta_{2}^{*}-g_{2}^{*}\right) .
\end{gathered}
$$

The coefficients of the above equation are the partial derivatives of $\varnothing$ presented in (35).

Substituting $d \omega$ in (A6) into (A4) and applying $(1-\delta) D=p_{2} \theta_{2}^{*}$ and $\delta=\omega p_{2}^{\prime} / p_{2}$ given in (4) to the result leads to

$$
\begin{gathered}
d c^{*}=-\rho d b+\left(\frac{\delta(1-\delta)^{2}}{\delta(1-\delta)+\omega \delta^{\prime}}\right) d D-p_{1} d g_{1}^{*}-\left(\frac{\delta(1-\delta)}{\delta(1-\delta)+\omega \delta^{\prime}}\right) p_{2} d g_{2} \\
+\left(\frac{\omega \delta^{\prime}}{\delta(1-\delta)+\omega \delta^{\prime}}\right) p_{2} d\left(\theta_{2}^{*}-g_{2}^{*}\right), \\
d c\left(=d D-d c^{*}\right)=\rho d b+\left(\frac{\delta^{2}(1-\delta)+\omega \delta^{\prime}}{\delta(1-\delta)+\omega \delta^{\prime}}\right) d D+p_{1} d g_{1}^{*}+\left(\frac{\delta(1-\delta)}{\delta(1-\delta)+\omega \delta^{\prime}}\right) p_{2} d g_{2}
\end{gathered}
$$




$$
-\left(\frac{\omega \delta^{\prime}}{\delta(1-\delta)+\omega \delta^{\prime}}\right) p_{2} d\left(\theta_{2}^{*}-g_{2}^{*}\right) .
$$

Because $d D$ is given by (34) and (35), $d c$ and $d c^{*}$ above turn to those in (36) and (37). 


\section{References}

Adolfson M., S. Laséen, J. Lindé and M. Villani (2007) “Bayesian Estimation of an Open Economy DSGE Model with Incomplete Pass-through”, Journal of International Economics, Vol. 72, pp. 481-511.

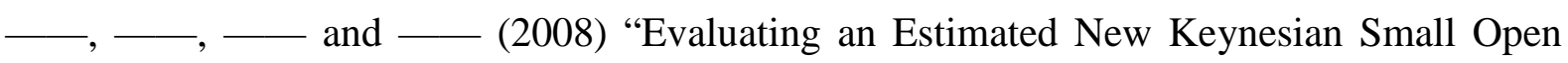
Economy Model”, Journal of Economic Dynamics and Control, Vol. 32, pp. 2690-2721. Akerlof, G. A. (1982) “Labor Contracts as Partial Gift Exchange”, Quarterly Journal of Economics, Vol. 97, pp. 543-569.

- and J. L. Yellen (1990) “The Fair-Wage Effort Hypothesis and Unemployment”, Quarterly Journal of Economics, Vol. 105, pp. 255-284.

Bhagwati, J. N., R. A. Brecher and T. Hatta (1983) “The Generalized Theory of Transfers and Welfare: Bilateral Transfers in a Multilateral World”, American Economic Review, Vol. 73, pp. 606-618.

— _ _ and _ (1983) “The Generalized Theory of Transfers and Welfare: Exogenous (Policy-Imposed) and Endogenous (Transfer-Induced) Distortions”, Quarterly Journal of Economics, Vol. 100, pp. 697-714.

Blanchard, O. J. and Fischer, S. (1989) Lectures on Macroeconomics, Cambridge, Mass.: The MIT Press.

Brandt Commission (1980) North-South: A Programme for Survival, London: Pan Books

— (1983) Common Crisis North-South: Cooperation for World Recovery, Cambridge, Mass.: The MIT Press.

Calvo, G. (1983) “Staggered Prices in a Utility Maximizing Framework”, Journal of Monetary Economics, Vol. 12, pp. 383-398.

Christiano, Lawrence J., Martin Eichenbaum, and Charles L. Evance (2005), "Nominal Rigidities and the Dynamic Effects of a Shock to Monetary Policy”, Journal of Political 
Economy, Vol. 113, pp. 1-45.

Deaton, A. and J. Muellbauer (1980) Economics and Consumer Behavior, Cambridge: Cambridge University Press.

Erceg, C. J., W. H. Dale and A. T. Levin (2000), “Optimal Monetary Policy with Staggered Wage and Price Contracts”, Journal of Monetary Economics, Vol. 46, pp. 281-313.

Hau, H. (2000), "Exchange Rate Determination: the Role of Factor Price Rigidities and Nontradables,” Journal of International Economics, Vol. 50, pp. 421-447.

Krugman, P. R. (1998) “It’s Baaack: Japan’s Slump and the Return of the Liquidity Trap”, Brookings Papers on Economic Activity, Vol. 2, pp. 137-187.

Lane, P. R. (2001), “The New Open Economy Macroeconomics: A Survey”, Journal of International Economics, Vol. 54, pp. 235-66.

Obstfeld M., and K. Rogoff (1995), “Exchange Rate Dynamics Redux”, Journal of Political Economy, Vol. 103, pp. 624-660.

Ono, Y. (1994) Money, Interest, and Stagnation, Oxford University Press.

— (2001), “A Reinterpretation of Chapter 17 of Keynes’s General Theory: Effective Demand Shortage under Dynamic Optimization”, International Economic Review, Vol. 42, pp. 207-236.

(2006), “International Asymmetry in Business Activity and Appreciation of a Stagnant Country's Currency”, Japanese Economic Review, Vol. 57, pp. 101-120.

_ (2007), “International Transfer under Stagnation”, in Theory and Practice of Foreign Aid, ed. by S. Lahiri, Elsevier: Amsterdam, pp. 155-171.

_ (2014), "International Economic Interdependence and Exchange-rate Adjustment under Persistent Stagnation”, Japanese Economic Review, Vol. 65, pp. 70-92.

— and J. Ishida (2014), “On Persistent Demand Shortages: A Behavioral Approach”, Japanese Economic Review, Vol. 65, pp. 42-69. 
— with Dynamic Optimizing Agents”, Japanese Economic Review, Vol. 55, pp. 355-371. Polemarchakis, H. M. (1983) “On the Transfer Paradox”, International Economic Review, Vol. 24, No. 3, pp. 749-760.

Smets, F., and R. Wouters (2003), “An Estimated Stochastic Dynamic General Equilibrium Model of the Euro Area”, Journal of the European Economic Association, Vol. 1, pp. 1123-1175.

— and _ (2005) "Bayesian New Neoclassical Synthesis (NNS) Models: Modern Tools for Central Banks”, Journal of the European Economic Association, Vol. 3, pp. 422-433.

— and — (2007), "Shocks and Frictions in US Business Cycles: A Bayesian DSGE Approach”, American Economic Review, Vol. 97, pp. 586-606.

Summers, L. (2013) "14th Annual IMF Research Conference: Crises Yesterday and Today, Nov. 8, 2013” available at http://www.youtube.com/watch?v=KYpVzBbQIX0.

Yun, T. (1996) “Nominal Price Rigidity, Monetary Supply Endogeneity, and Business Cycles”, Journal of Monetary Economics, Vol. 37, pp. 345-370. 


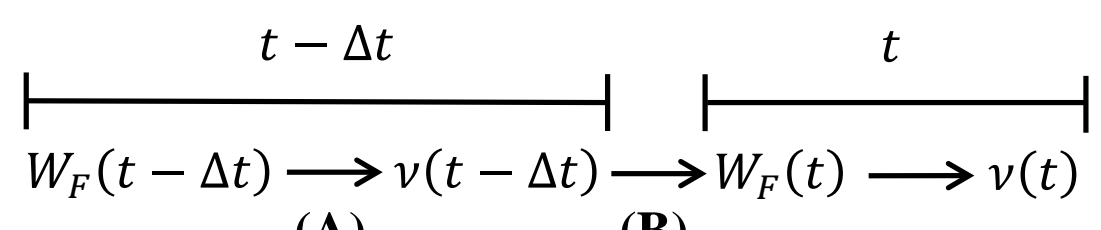

(A)

(B)

Figure 1: Timing of Fair-Wage Determination 


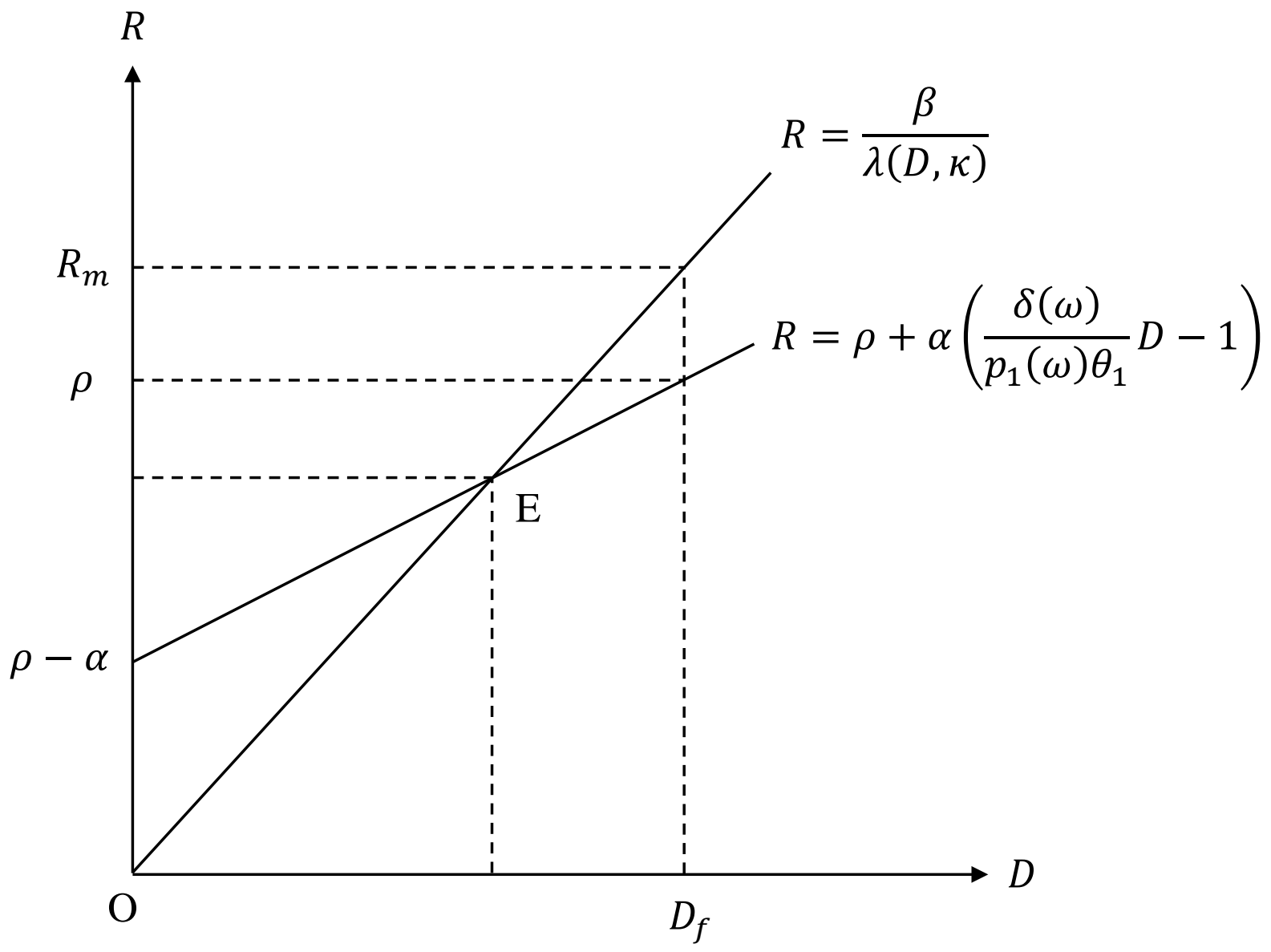

Figure 2: Stagnation steady state 